\title{
Outcome of pediatric heart transplantation in blood culture positive donors in the United States
}

\author{
Shahnawaz M. Amdani ${ }^{1}$ (D) $\mid$ Wei $^{2}{ }^{2}$ | Sanjeev Aggarwal ${ }^{3}$
}

${ }^{1}$ Division of Pediatric Cardiology, St. Louis Children's Hospital, Washington University School of Medicine, St. Louis, MO, USA

${ }^{2}$ The Carman and Ann Adams Department of Pediatrics, The Children's Hospital of Michigan, Wayne State University School of Medicine, Detroit, MI, USA

${ }^{3}$ Division of Pediatric Cardiology, The Carman and Ann Adams Department of Pediatrics, The Children's Hospital of Michigan, Wayne State University School of Medicine, Detroit, MI, USA

\section{Correspondence}

Shahnawaz M. Amdani, MBBS, MD, Division of Pediatric Cardiology, St. Louis Children's Hospital, Washington University School of Medicine, St. Louis, MO, USA.

Email: shaanamdani@gmail.com

Funding information

This research did not receive any specific grant from funding agencies in the public, commercial, or not-for-profit sectors.

\begin{abstract}
Active donor infection at the time of organ procurement poses a potential infection risk and may increase post-transplant morbidity and mortality in recipients. Our hypothesis was that pediatric heart transplant recipients from blood culture positive donors (BCPD) would have increased morbidity and mortality compared to nonblood culture positive donors (NBCPD). A retrospective analysis of pediatric heart transplant recipients using the organ procurement and transplant network (OPTN) between 1987 and 2015 was conducted. Recipient as well as donor data were analyzed. Propensity score matching with 1:2 ratios was performed for recipient variables. Post-transplant morbidity and mortality were compared for recipients of BCPD and NBCPD. Among 9618 heart transplant recipients, 450 (4.7\%) were from culture positive donors. Recipients of BCPD had longer duration of listing as Status 1; diagnosis of congenital heart disease or restrictive cardiomyopathy and required support (IV inotropes, Inhaled NO and LVAD) prior to transplant. Post-transplant survival between the 2 groups was not different. Propensity-matched recipients had similar length of stay; stroke rate; need for dialysis; pacemaker implantation and treated rejection episodes in the first year post-transplant. Careful acceptance of BCPD may have the potential to increase availability of donor hearts in the pediatric population.
\end{abstract}

\section{KEYWORDS}

blood culture positive donors, pediatric heart transplant, transplant outcomes, United

Network of Organ Sharing

\section{1 | INTRODUCTION}

Heart transplantation is routinely offered to children with end-stage heart failure due to cardiomyopathies or secondary to congenital heart diseases (CHD). ${ }^{1-4}$ In recent years, survival outcomes for $\mathrm{CHD}$ surgery have improved. ${ }^{5-7}$ Hence, in addition to children there is now an increasing flux of adults with congenital heart disease requiring heart transplantation..$^{8,9}$

Limited donor availability of hearts remains a challenge, hence measures to maximize the donor pool are warranted. One of the many ways to increase the availability of organs is using high-risk donors or suboptimal organs. Pediatric studies using high-risk donors, donors previously refused and donors with depressed ventricular function have been successful. ${ }^{10-12}$

Donor-transmitted infections are known to occur in 0.2\%-1.7\% of all transplant procedures. ${ }^{13,14}$ Immunosuppressant use following organ transplantation further lowers immunity, ${ }^{15-17}$ making the recipients more susceptible to overt clinical infection or cause reactivation of a latent infection. Such infections, in turn increase posttransplant morbidity and mortality in heart transplant recipients. ${ }^{18,19}$

A recent multi-center study by Forest et $\mathrm{al}^{20}$ evaluated short and long-term heart transplant outcomes in adults following heart 
transplantation from blood culture positive donors (BCPD) vs nonblood culture positive donors (NBCPD). Recipients of BCPD had higher rates of co-morbidities, but overall survival was no different at 1 year ( $86 \%$ vs $87 \%, P=.2585)$ and at 15 years (34\% vs $36 \%$, $P=.0929)$. There is paucity of data, however, on post-transplant outcomes of pediatric recipients receiving hearts from BCPD. In this study, we compared morbidity and mortality outcomes of pediatric patients who received hearts from BCPD vs NBCPD.

\section{2 | METHODS}

\section{1 | Study design and data collection}

This was a retrospective analysis of data obtained from the United Network of Organ Sharing Database (UNOS) Standard Transplant Analysis and Research files. UNOS is the regulatory agency responsible for the oversight of all solid organ transplantation in the United States. UNOS data include donor and recipient characteristics and follow-up outcomes of all patients who have undergone solid organ transplantation. The study was determined to be exempt from review by the Institutional Review Board of the Children's Hospital of Michigan and Wayne State University as all protected health information was de-identified.

Pediatric patients $\leq 18$ years of age, either gender, undergoing single organ (heart) transplantation in the United States from 19872015 were included in this study. Adult patients ( $>18$ years) and multi-organ transplants were excluded. Moreover, outcome variables with $<50 \%$ reported values were excluded from analysis.

Donor variables included for analysis were as follows: age, gender, ethnicity, weight, body surface area (BSA), body mass index (BMI), ABO blood type, cause of death, hepatitis $B$ and hepatitis $C$ status, cytomegalovirus (CMV) status, tattoos, source of infection (pulmonary, urine, other), risk status for blood-borne transmission, history of drug abuse (cocaine, intravenous [IV] or other drug use), ischemic time, receipt of IV inotropes, previous cardiopulmonary resuscitation (CPR), and left ventricular ejection fraction.

Recipient variables included for analysis were: age, gender, ethnicity, weight, BSA, BMI, days listed as UNOS status 1, primary transplant vs re-transplant, primary cardiac diagnosis-dilated cardiomyopathy (DCM), restrictive cardiomyopathy (RCM), hypertrophic cardiomyopathy (HCM), congenital heart disease, heart re-transplant and other), $A B O$ blood type, patient status prior to transplant (out of hospital, in hospital, ICU), support prior to transplant (ventilator, ECMO, IABP, IV inotropes, dialysis, inhaled nitric oxide, other), ventricular assist device (VAD) use prior to transplant, panel-reactive antibody (PRA), prior cardiac surgery, serum albumin, year of transplant, infection requiring IV drug therapy 2 weeks before transplant, and donor-recipient $A B O$ match.

Our primary outcome was patient survival post-transplant. Our secondary outcomes were post-transplant hospital length of stay, events prior to hospital discharge (stroke, dialysis, pacemaker implantation), and treated rejection episodes in the first year post-transplant.

\section{2 | Statistical analysis}

Summary statistics are presented as median (interquartile range), mean [95\% confidence interval], or number (percent) as appropriate. Recipient and donor characteristics were compared across groups using the chi-square or Fischer's exact tests for categorical variables and the Student's $t$ test or Wilcoxon rank sum test for continuous variables, as appropriate, depending upon variable distribution. Cochrane-Armitage test was utilized to evaluate trend of utilization of BCPD overtime.

SAS PSMATCH ${ }^{21}$ procedure utilizing the optimal method of propensity score matching with 1:2 ratios was performed to achieve unbiased estimation of treatment effect in an observational study. Optimal method selects all matches simultaneously without replacement to minimize the total absolute difference in propensity score across all matches. The variables used in the above procedure included gender, ethnicity (white vs non-white), ventilator, ECMO, VAD and dialysis prior to transplant, underlying diagnosis (congenital heart disease vs others), year of transplant (before 2010 vs 2010 and after), days as status 1 ( $\leq 7$ days, $8-30$ days, $>30$ days), and age ( $<1$ year, 1-10 years, 10-18 years). The PSMATCH procedure resulted in 449 cases and 898 controls.
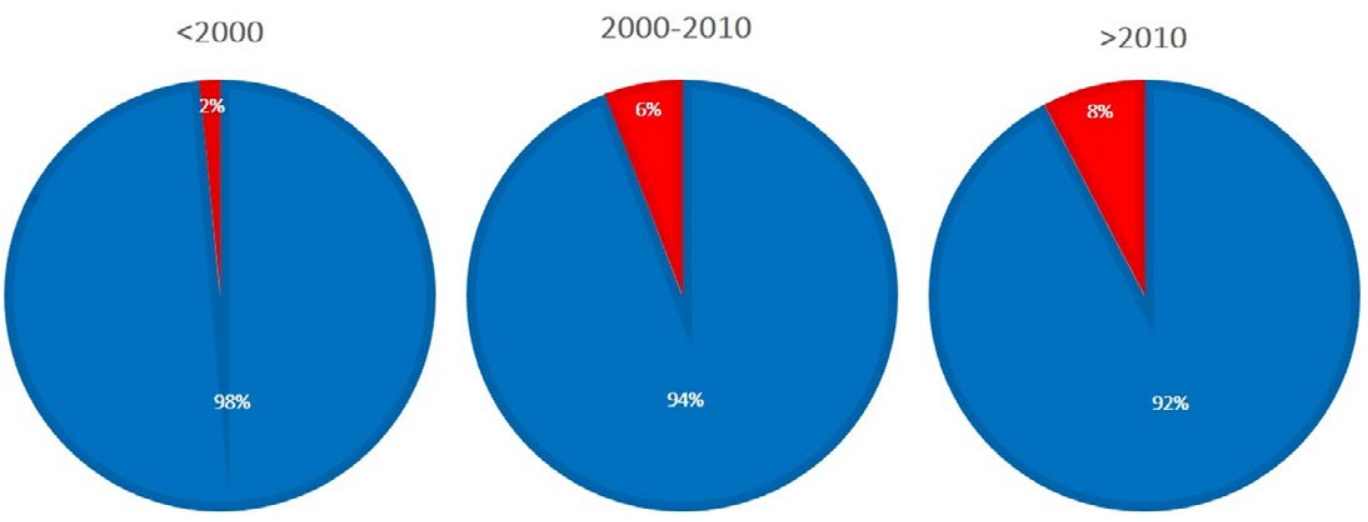

Blood culture negative

FIG URE 1 Trend in utilization of blood culture positive donors over time $(P<.0001)$ 
TAB LE 1 Demographic and clinical characteristics of donors

\begin{tabular}{|c|c|c|c|c|}
\hline & $\begin{array}{l}\text { No. of Patients } \\
n=9618 \\
n(\%)\end{array}$ & $\begin{array}{l}\text { BCPD } \\
n=450 \\
\text { Mean }[95 \% \mathrm{Cl}] \text {, or } n(\%)\end{array}$ & $\begin{array}{l}\text { NBCPD } \\
n=9168 \\
\text { Mean }[95 \% \mathrm{Cl}] \text {, or } n(\%)\end{array}$ & $P$ value \\
\hline $0-\leq 1$ & $8714(90.6)$ & $83(20.3)$ & $1953(23.5)$ & \multirow[t]{2}{*}{$.04^{*}$} \\
\hline $1-10$ & & $136(33.4)$ & 2945 (35.5) & \\
\hline Weight & $9126(94.9)$ & $34.8[32.4-37.2]$ & $32.6[32.1-33.1]$ & .08 \\
\hline Donor BMI & $8563(89)$ & $19.6[19.1-20]$ & 19.1 [19-19.2] & .06 \\
\hline \multicolumn{5}{|l|}{ Gender } \\
\hline Male & 9617 (99.9) & $250(55.6)$ & $5240(57.2)$ & .53 \\
\hline African American & & $105(23.8)$ & 1704 (19) & \multirow{3}{*}{$.001^{*}$} \\
\hline Hispanic & & $94(21.3)$ & $1530(17)$ & \\
\hline Other & & $7(1.6)$ & $136(1.5)$ & \\
\hline \multicolumn{5}{|l|}{ ABO blood type } \\
\hline $\mathrm{O}$ & 9448 (98.2) & $286(63.6)$ & $5421(60.3)$ & .51 \\
\hline \multicolumn{5}{|l|}{ Cause of death } \\
\hline Anoxia $^{a}$ & 9485 (98.6) & $86(19.1)$ & $1254(13.9)$ & \multirow[t]{3}{*}{$<.0001^{*}$} \\
\hline Trauma $^{\mathrm{b}}$ & & $190(42.2)$ & 4039 (44.7) & \\
\hline Cardiovascular & & $30(6.7)$ & $564(6.2)$ & \\
\hline Donor tattoos & $9618(100)$ & $35(7.8)$ & $490(5.3)$ & $.03^{*}$ \\
\hline \multicolumn{5}{|l|}{ Donor source of infection } \\
\hline Pulmonary & $9618(100)$ & $292(64.9)$ & $2142(23.4)$ & \multirow[t]{3}{*}{$<.0001^{*}$} \\
\hline Urine & & $186(41.3)$ & $502(5.5)$ & \\
\hline Other & & 47 (10.4) & 302 (3.3) & \\
\hline $\begin{array}{l}\text { Donor at risk for blood- } \\
\text { borne disease } \\
\text { transmission }^{d}\end{array}$ & $9618(100)$ & $20(4.4)$ & $217(2.4)$ & $.01^{*}$ \\
\hline \multicolumn{5}{|l|}{ Source of infection } \\
\hline Pulmonary & $9618(100)$ & $292(64.9)$ & $2142(23.4)$ & \multirow[t]{3}{*}{$<.0001^{*}$} \\
\hline Urine & & $186(41.3)$ & $502(5.5)$ & \\
\hline Other & & $47(10.4)$ & $302(3.3)$ & \\
\hline \multicolumn{5}{|c|}{ Donor history of drug abuse } \\
\hline Cocaine & $9618(100)$ & $4(0.9)$ & $62(0.7)$ & .55 \\
\hline IV drug use & & $0(0)$ & $11(0.12)$ & 1 \\
\hline Other drug use & & $28(6.2)$ & $448(4.9)$ & .22 \\
\hline Ischemic time $>4$ & $9618(100)$ & $186(41.3)$ & $3312(36.1)$ & $.03^{*}$ \\
\hline
\end{tabular}


TABLE 1 (Continued)

\begin{tabular}{|c|c|c|c|c|}
\hline & $\begin{array}{l}\text { No. of Patients } \\
n=9618 \\
n(\%)\end{array}$ & $\begin{array}{l}\text { BCPD } \\
n=450 \\
\text { Mean }[95 \% \mathrm{Cl}] \text {, or } n(\%)\end{array}$ & $\begin{array}{l}\text { NBCPD } \\
n=9168 \\
\text { Mean }[95 \% \mathrm{Cl}] \text {, or } \mathrm{n}(\%)\end{array}$ & $P$ value \\
\hline $\begin{array}{l}\text { Vasoactive support at } \\
\text { procurement }\end{array}$ & 9618 (100) & $186(41.3)$ & $2446(26.7)$ & $<.0001^{*}$ \\
\hline Previous CPR & 9618 (100) & $27(6)$ & 451 (4.9) & .32 \\
\hline $\begin{array}{l}\text { Donor left ventricular } \\
\text { ejection fraction }\end{array}$ & $5713(59.4)$ & 63.6 [62.5-64.6] & $62.8[62.5-63.1]$ & .17 \\
\hline
\end{tabular}

BCPD, blood culture positive donors; NBCPD, non-blood culture positive donors.

aDrowning, seizure, asphyxiation.

${ }^{b}$ Gunshot wound, stab, gunshot/stab wound, blunt injury, electrical.

${ }^{\mathrm{c}}$ SIDS, intracranial hemorrhage/stroke, death from natural causes, none of the above.

${ }^{\mathrm{d}}$ Refers to Public Health Service increased risk donors, which are donors deemed to be at higher risk for HIV prior to 2013 and HIV, HBV, and HCV after 2013. ${ }^{*} \mathrm{P}<.05$

The characteristics and outcomes of the 2 study groups were compared using $\mathrm{t}$ tests and chi-square tests after the propensity score matching. Kaplan-Meier survival curves along with log-rank test were used to compare graft and overall survival of the 2 study groups. The conventional $P$-value $<.05$ was used to determine statistical significance. All data analyses were performed using SAS version 9.4 (SAS Inc., Cary, NC, USA).

\section{3 | RESULTS}

A total of 9618 pediatric heart transplants were performed during the study period and 450 (4.7\%) children received organs from $B C P D$. There was a progressive increase in utilization of BCPD for heart transplantation over the years $(P<.0001)$ (Figure 1 ).

\section{1 | Donor characteristics}

Demographic characteristics of BCPD and NBCPD were similar with respect to gender, weight, $\mathrm{BMI}, \mathrm{ABO}$ blood type, and hepatitis $\mathrm{B}$ and $C$ status. BCPD were more likely to be older (11-18 years $[29.9 \%$ vs $23.8 \%, P=.04]$ ), of African American or Hispanic ethnicity $(23.8 \%$ vs $19 \% ; 21.3 \%$ vs $17 \%$ respectively, $P=.001)$, have died from anoxia $(19.1 \%$ vs $13.9 \%, P<.0001)$ or drug intoxication (3.6\% vs $1.2 \%$, $P<.0001)$, and more likely to have tattoos (7.8\% vs $5.3 \%, P=.03$ ) on their body. Moreover, they were more likely $(4.4 \%$ vs $2.4 \%$, $P=.01$ ) to be a Public Health Service increased risk donor (donors which were deemed to be at higher risk for HIV prior to 2013 and HIV, HBV, and HCV after 2013), and to have a source of infection. History of drug abuse, however, was no different between 2 groups (Table 1).

\section{2 | Recipient characteristics}

Recipients of BCPD were no different than NBCPD with respect to age, gender, weight, $\mathrm{BMI}$, and previous history of transplant. However, recipients of BCPD were listed for a longer duration as
UNOS status 1 (34.6 [29.4-39.9] vs 24.9 [23.8-26.1] days, $P=.0004)$, more frequently had a history of congenital heart disease $(19.1 \%$ vs $13.7 \% ; P=.0003)$ or restrictive cardiomyopathy $(6.4 \%$ vs $4.3 \%$, $P=.0003)$, and were more likely to be on IV inotropic support (46.2\% vs $38.3 \%, P=.0009)$ and inhaled nitric oxide (1.3\% vs $0.5 \%, P=.02)$ prior to transplant. Also, recipients of BCPD were more likely to be on left ventricular assist device (LVAD) support (8.2 vs 4.5, $P=.0009$ ) prior to transplant. Moreover, recipients of BCPD were more likely to have received IV drug therapy for infection 2 weeks prior to transplant $(25.3 \%$ vs $16.3 \%, P<.0001)$ (Table 2$)$.

\section{3 | Post-transplant outcomes of recipients from BCPD vs NBCPD}

There were no differences in median patient survival between unmatched recipients of BCPD and NBCPD $(P=.15)$ (Figure 2A). In the matched cohort, there was no difference in 1-month survival $(94.1 \%$ vs $95.1 \%, P=.51$ ) and 6 -month survival ( $88.9 \%$ vs $89.9 \%, P=.63$ ) post-transplant. Moreover, long-term patient survival between matched recipients was also no different $(P=.72)$ (Figure 2B).

Propensity-matched BCPD and NBCPD recipients had similar hospital length of stay (27.2 [24.3-30.2] vs 27.5 [25.3-29.7] days, $P=.90)$, stroke rate (3.2\% vs $2.4 \% ; P=.36$ ), need for dialysis ( $7 \%$ vs $6.9 \%, P=.91$ ), and pacemaker implantation (0.9 vs $1.1, P=1$ ) posttransplant. The numbers of treated rejection episodes in the first year post-transplant were also no different between both groups (28.7\% vs $29.2 \%, P=.88$ ) (Table 3 ).

\section{4 | DISCUSSION}

Most recent UNOS/OPTN estimates (2011-2014) reveal that median waiting times for pediatric patients listed for heart transplants ranged from 72-188 days (the longest for children 1-5 years of age). ${ }^{22}$ During the same time, the number of pediatric patients who were successfully transplanted was around $61.4 \%-74.5 \%$ with the lowest number in infants. In view of the limited supply of donor 
TAB LE 2 Demographic and clinical characteristics of recipients

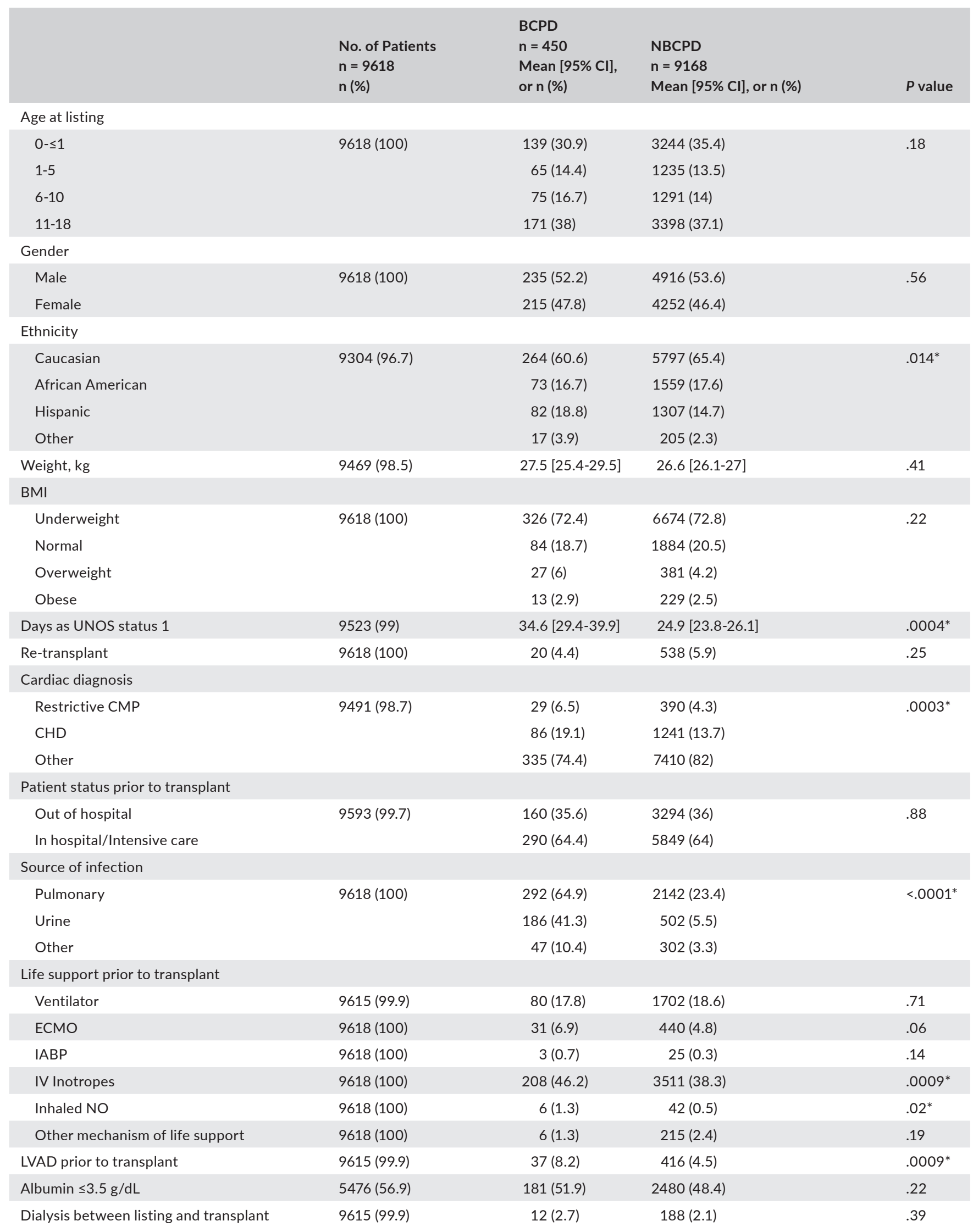


TABLE 2 (Continued)

\begin{tabular}{|c|c|c|c|c|}
\hline & $\begin{array}{l}\text { No. of Patients } \\
n=9618 \\
n(\%)\end{array}$ & $\begin{array}{l}\text { BCPD } \\
n=450 \\
\text { Mean }[95 \% \mathrm{Cl}] \\
\text { or } n(\%)\end{array}$ & $\begin{array}{l}\text { NBCPD } \\
n=9168 \\
\text { Mean }[95 \% \mathrm{Cl}], \text { or } n(\%)\end{array}$ & $P$ value \\
\hline $\begin{array}{l}\text { Infection requiring IV drug therapy } 2 \mathrm{wk} \\
\text { before transplant }\end{array}$ & $9618(100)$ & $114(25.3)$ & $1491(16.3)$ & $<.0001^{*}$ \\
\hline \multicolumn{5}{|l|}{ Donor-recipient blood type } \\
\hline Donor-recipient weight ratio & $9036(93.9)$ & $1.36[1.32-1.41]$ & $1.38[1.37-1.39]$ & .49 \\
\hline \multicolumn{5}{|l|}{ Total bilirubin } \\
\hline$>2 \mathrm{mg} / \mathrm{dL}$ & 7299 (75.9) & $59(14.5)$ & $996(14.5)$ & 1 \\
\hline
\end{tabular}

BCPD, blood culture positive donors; LVAD, left ventricular assist device; NBCPD, non-blood culture positive donors; UNOS, United Network of Organ Sharing. ${ }^{*} P<.05$.

(A) Product-Limit Survival Estimates

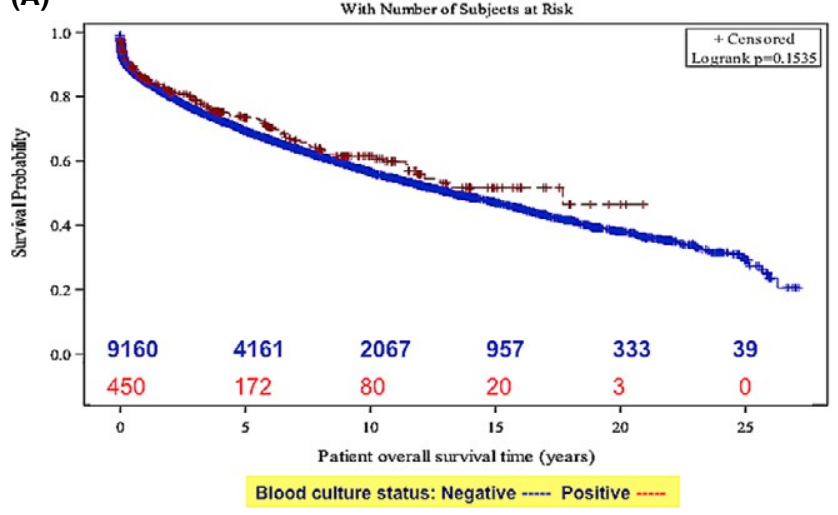

(B)

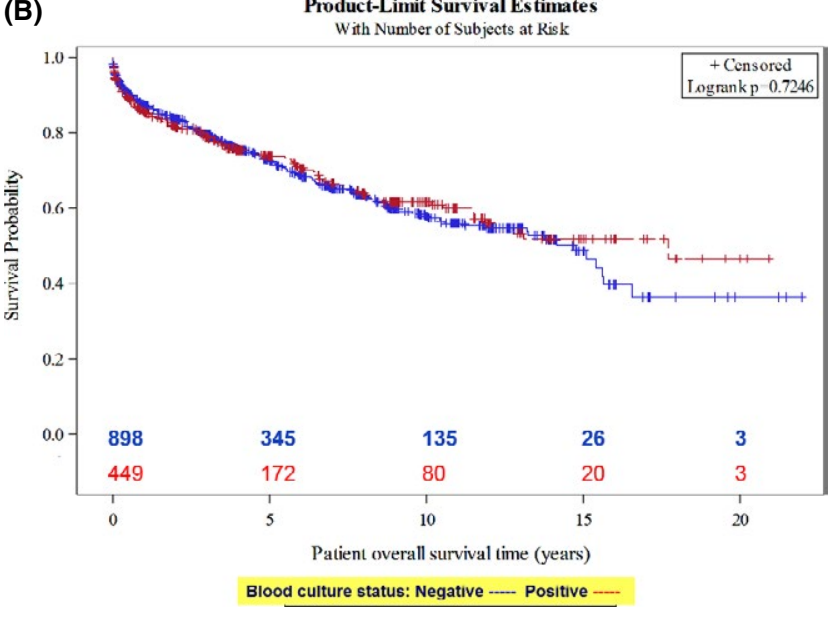

FIGURE 2 Kaplan-Meier survival outcomes for patients transplanted with blood culture positive vs negative donors. A, Unmatched cohort. B, Propensity-matched cohort

hearts, there has been a quest to evaluate outcomes following heart transplantation from suboptimal donors.

In our study, blood culture positive donors were utilized for transplants in only a minority of patients (4.7\%). Whether this was because of fewer BCPD in the United States or the fact that there was low utilization of such donors is not known. It has been shown that there is a risk of transmitting donor infections to the recipient via transplant and such infections can increase early and late morbidity and mortality. ${ }^{13,14,23-27}$ Moreover, pediatric patients do not have as many comorbidities (diabetes, hypertension, and end-stage renal disease) as adults and hence centers tend to wait for an "ideal" donor organ. ${ }^{28,29}$ Thus the donor pool is often limited for use by these patients.

Although ideally transplanting centers would like to have all information (clinical and microbiological) about the donor, time constraints in which such screening must be carried out make it less likely that transplanting centers would have all this information until after transplant. ${ }^{30}$ In our study, we found characteristics of donors who were more likely to be blood culture positive (adolescent, of African American or Hispanic ethnicity, death from drug intoxication, and have other focus of infection). These characteristics may be used by the recipient center as a screening tool to identify such donors.

As expected, recipients who received BCPD had higher acuity of illness at time of transplant (longer duration as UNOS status 1, underlying cardiac diagnosis of congenital heart disease or restrictive cardiomyopathy, on IV inotropes, inhaled nitric oxide, and VAD support pretransplant) and would have likely died on the waitlist as shown in other studies ${ }^{31-35}$ if centers had not accepted a BCPD. Interestingly, recipients of BCPD were more likely to have received IV drug therapy for infection in the 2 weeks prior to transplant. These patients were probably more prone to infection because they were more likely to have been on ECMO or VAD support, both of which are known to be associated with an increased infection risk. ${ }^{36-40}$

The survival in both unmatched and propensity-matched analyses was comparable between BCPD and non-BCPD groups. Morbidities and hospital length of stay were also similar. These results, given the higher acuity of the BCPD recipients, are encouraging. These findings are similar to the adult study evaluating outcomes of blood culture positive donors in kidney, ${ }^{41}$ liver, ${ }^{42}$ and heart transplantation. ${ }^{20}$ Selective use of PHS "increased risk" donors has been shown in other analysis to result in similar post-transplant survival. ${ }^{10}$ Donors at high risk of positive blood culture or those with known positive blood culture likely comprise some of this "increased risk" pool for which post-transplant survival is not impacted and therefore if all else with 
TAB LE 3 Post-transplant outcomes in patients transplanted with blood culture positive vs propensity-matched non-blood culture positive donors

\begin{tabular}{|c|c|c|c|}
\hline & $\begin{array}{l}\text { BCPD } \\
n=449 \\
\text { Mean }[95 \% \mathrm{Cl}], \text { or } n(\%)\end{array}$ & $\begin{array}{l}\text { NBCPD } \\
n=898 \\
\text { Mean }[95 \% \mathrm{Cl}] \text {, or } \mathrm{n}(\%)\end{array}$ & $P$ value \\
\hline $\begin{array}{l}\text { Hospital length of } \\
\text { stay (d) }\end{array}$ & 27.2 [24.3-30.2] & 27.5 [25.3-29.7] & .90 \\
\hline Stroke & $14(3.2)$ & $20(2.4)$ & .36 \\
\hline Dialysis & $31(7)$ & $59(6.9)$ & .91 \\
\hline $\begin{array}{l}\text { Pacemaker } \\
\text { implantation }\end{array}$ & $4(0.9)$ & $9(1.1)$ & 1 \\
\hline $\begin{array}{l}\text { Treated rejection } \\
\text { episodes in first } \\
\text { year post-transplant }\end{array}$ & $86(28.7)$ & 195 (29.2) & .88 \\
\hline
\end{tabular}

BCPD, blood culture positive donors; NBCPD, non-blood culture positive donors. the donor seems suitable for transplant (considering the candidate's risk profile) then donor should not be declined solely on the basis of positive blood culture or likely positive blood culture.

Certain measures can be taken to decrease transmission of donor-derived infections to the recipients. Such measures include (i) surveillance cultures of the transplant recipient to detect any infection post-transplant and (ii) depending on the organism isolated from the donor, post-transplant antibiotics directed against the organism for appropriate duration. ${ }^{43-46}$ The use of BCPD, along with active surveillance and judicious use of antibiotics in such recipients, will allow an expansion of the donor pool for pediatric heart transplant recipients without increasing morbidity and mortality.

\section{1 | Study limitations}

Our study is based on analysis of registry data, which often depends on accurate data input by the participating centers. Post-transplant outcomes such as early in-hospital mortality, post-transplant sepsis, long-term morbidity, and coronary allograft vasculopathy were not available and hence could not be analyzed. We limited the outcomes analysis to only those variables that had more than $50 \%$ reported rates, thus reducing but definitely not eliminating a type II error. We did not have detailed information about the bacterial strains. This information is important as virulent bacterial infections may have worse post-transplant outcomes than communityacquired bacteria. Also, there is a possibility that a portion of blood culture positive donors may include individuals who have cultures that are positive for common contaminants such as coagulase-negative staphylococcus, which may not increase post-transplant morbidity or mortality. Finally, we did not have information for blood culture positive donors that never got utilized for transplantation. Whether the BCPD who were accepted for transplantation differed in some systematic way from those that were not accepted is unknown, and certainly possible.

\section{5 | CONCLUSIONS}

In this study, we utilized the largest national transplant registry to assess the characteristics and outcomes of BCPD in the pediatric population. Recipients of such BCPD donors were more likely to have higher acuity of illness and a higher likelihood of dying while waiting for transplant. Even though recipients of BCPD were sicker, post-transplant morbidity and mortality was not inferior to recipients receiving NBCPD. These findings suggest that careful acceptance of BCPD may have the potential to increase the availability of donor hearts without increasing post-transplant morbidity and mortality in children with end-stage heart failure.

\section{ACKNOWLEDGEMENT}

This work was supported in part by Health Resources and Services Administration contract 234-2005-37011C. The content is the responsibility of the authors alone and does not necessarily reflect the views or policies of the Department of Health and Human Services, nor does mention of trade names, commercial products, or organizations imply endorsement by the U.S. Government.

\section{CONFLICT OF INTEREST}

The authors have no conflict of interests to disclose.

\section{ORCID}

Shahnawaz M. Amdani iD http://orcid.org/0000-0001-8489-3181

\section{REFERENCES}

1. Hsu DT, Pearson GD. Heart failure in children: part II: diagnosis, treatment, and future directions. Circ Heart Fail. 2009;2:490-498.

2. Webster G, Zhang J, Rosenthal D. Comparison of the epidemiology and co-morbidities of heart failure in the pediatric and adult populations: a retrospective, cross-sectional study. BMC Cardiovasc Disord. 2006;6:23.

3. Sommers $\mathrm{C}$, Nagel $\mathrm{BH}$, Neudorf $\mathrm{U}$, et al. Congestive heart failure in childhood. An epidemiologic study. Herz. 2005;30:652-662.

4. Massin MM, Astadicko I, Dessy H. Epidemiology of heart failure in a tertiary pediatric center. Clin Cardiol. 2008;31:388-391. 
5. Boneva RS, Botto LD, Moore CA, et al. Mortality associated with congenital heart defects in the United States: trends and racial disparities, 1979-1997. Circulation. 2001;103:2376-2381.

6. Talner $\mathrm{CN}$. Report of the new england regional infant cardiac program, by Donald C. Fyler, MD, pediatrics, 1980; 65 (suppl): 375-461. Pediatrics. 1998;102(Supp 1):258-259.

7. McGuirk SP, Stickley J, Griselli M, et al. Risk assessment and early outcome following the Norwood procedure for hypoplastic left heart syndrome. Eur J Cardiothorac Surg. 2006;29:675-681.

8. Burchill LJ. Heart transplantation in adult congenital heart disease. Heart. 2016;102:1871-1877.

9. Stehlik J, Edwards LB, Kucheryavaya AY, et al. The Registry of the International Society for Heart and Lung Transplantation: 29th official adult heart transplant report-2012. J Heart Lung Transplant. 2012;31:1052-1064.

10. Gaffey AC, Doll SL, Thomasson AM, et al. Transplantation of "highrisk" donor hearts: implications for infection. J Thorac Cardiovasc Surg. 2016;152:213-220.

11. Easterwood R, Singh RK, McFeely ED, et al. Pediatric cardiac transplantation using hearts previously refused for quality: a single center experience. Am J Transplant. 2013;13:1484-1490.

12. Rossano JW, Lin KY, Paridon SM, et al. Pediatric heart transplantation from donors with depressed ventricular function: an analysis of the United Network of Organ Sharing Database. Circ Heart Fail. 2013;6:1223-1229.

13. Grossi PA, Costa AN, Fehily D, et al. Infections and organ transplantation: new challenges for prevention and treatment-a colloquium. Transplantation. 2012;93:S4-S39.

14. Len $\mathrm{O}$, Gavaldà J, Blanes $\mathrm{M}$, et al. Donor infection and transmission to the recipient of a solid allograft. Am J Transplant. 2008;8:2420-2425.

15. Fishman JA. Infection in solid-organ transplant recipients. $N$ Engl $J$ Med. 2007;357:2601-2614.

16. Bach M, Alder JL, Breman J, et al. Influence of rejection therapy on fungal and nocardial infections in renal-transplant recipients. Lancet. 1973;301:180-184.

17. Schmaldienst $\mathrm{S}$, Hörl W. Bacterial infections during immunosuppression-inmmunosuppressive agents interfere not only with immune response, but also with polymorphonuclear cell function. 1996, Oxford University Press.

18. Bull D, Stahl RD, McMahan DL, et al. The high risk heart donor: potential pitfalls. J Heart Lung Transplant. 1995;14:424-428.

19. Coll P, Montserrat I, Ballester M, et al. Epidemiologic evidence of transmission of donor-related bacterial infection through a transplanted heart. J Heart Lung Transplant. 1997;16:464-467.

20. Forest SJ, Friedmann P, Bello R, et al. Cardiac transplantation from infected donors: is it safe? J Card Surg. 2015;30:288-295.

21. Yuan Y, Yung Y-F, Stokes M. Propensity Score Methods for Causal Inference with the PSMATCH Procedure.

22. https://optn.transplant.hrsa.gov/data/view-data-reports/national-data/\#

23. Zibari G, Lipka J, Zizzi H, et al. The use of contaminated donor organs in transplantation. Clin Transplant. 2000;14:397-400.

24. Nery J, Weppler D, Olson L, et al. Donor Infection and Primary Nonfunction in Liver Transplantation. in Transplantation Proceedings. Philadelphia: Elsevier; 1997.

25. Singh N, Huprikar S, Burdette SD, et al. Donor-derived fungal infections in organ transplant recipients: guidelines of the American Society of Transplantation, Infectious Diseases Community of Practice. Am J Transplant. 2012;12:2414-2428.

26. Gasink LB, Blumberg EA, Localio AR, et al. Hepatitis C virus seropositivity in organ donors and survival in heart transplant recipients. JAMA. 2006;296:1843-1850.

27. Mathurin $\mathrm{P}$, Mouquet $\mathrm{C}$, Poynard $\mathrm{T}$, et al. Impact of hepatitis $\mathrm{B}$ and $\mathrm{C}$ virus on kidney transplantation outcome. Hepatology. 1999;29:257-263.
28. Feingold $B$. The challenges of donor-derived risk, donor shortage and waitlist mortality in children: time for a new measuring stick? J Heart Lung Transplant. 2018;37:317-318.

29. Bailey LL, Razzouk AJ, Hasaniya NW, Chinnock RE. Pediatric transplantation using hearts refused on the basis of donor quality. Ann Thorac Surg. 2009;87:1902-1908.

30. Fischer S, Lu K. Screening of donor and recipient in solid organ transplantation. Am J Transplant. 2013;13(s4):9-21.

31. Almond CS, Thiagarajan RR, Piercey GE, et al. Waiting list mortality among children listed for heart transplantation in the United States. Circulation. 2009;119:717-727.

32. Singh TP, Almond CS, Piercey G, Gauvreau K. Trends in wait-list mortality in children listed for heart transplantation in the United States: era effect across racial/ethnic groups. Am J Transplant. 2011;11:2692-2699.

33. Hsich E, Starling RC, Blackstone E, et al. Restrictive cardiomyopathy and risk of mortality on waiting list for heart transplantation. J Heart Lung Transplant. 2014;33:S66-S67.

34. Singh TP, Almond CS, Piercey G, Gauvreau K. Current outcomes in US children with cardiomyopathy listed for heart transplantationclinical perspective. Circ Heart Fail. 2012;5:594-601.

35. Zafar F, Castleberry C, Khan MS, et al. Pediatric heart transplant waiting list mortality in the era of ventricular assist devices. J Heart Lung Transplant. 2015;34:82-88.

36. Bizzarro MJ, Conrad SA, Kaufman DA, Rycus P. Infections acquired during extracorporeal membrane oxygenation in neonates, children, and adults. Pediatr Crit Care Med. 2011;12:277-281.

37. Burket JS, Bartlett RH, Vander Hyde K, Chenoweth CE. Nosocomia infections in adult patients undergoing extracorporeal membrane oxygenation. Clin Infect Dis. 1999;28:828-833.

38. Rose EA, Gelijns AC, Moskowitz AJ, et al. Long-term use of a left ventricular assist device for end-stage heart failure. N Engl J Med. 2001;345:1435-1443

39. Gordon SM, Schmitt SK, Jacobs M, et al. Nosocomial bloodstream infections in patients with implantable left ventricular assist devices. Ann Thorac Surg. 2001;72:725-730.

40. Gordon RJ, Quagliarello B, Lowy FD. Ventricular assist device-related infections. Lancet Infect Dis. 2006;6:426-437.

41. Huaman MA, Vilchez V, Mei X, Davenport D, Gedaly R. Donor positive blood culture is associated with delayed graft function in kidney transplant recipients: a propensity score analysis of the UNOS database. Clin Transplant. 2016;30:415-420.

42. Cerutti E, Stratta C, Romagnoli R, et al. Bacterial-and fungal-positive cultures in organ donors: clinical impact in liver transplantation. Liver Transpl. 2006;12:1253-1259.

43. Kovacs Jr CS, Koval CE, van Duin D, et al. Selecting suitable solid organ transplant donors: reducing the risk of donor-transmitted infections. World J Transplant. 2014:4:43-56.

44. Fishman JA, Greenwald MA, Grossi PA. Transmission of infection with human allografts: essential considerations in donor screening. Clin Infect Dis. 2012;55:720-727.

45. Grossi P, Fishman J. Donor-derived infections in solid organ transplant recipients. Am J Transplant. 2009;9(s4):S19-S26.

46. Freeman RB, Giatras I, Falagas ME, et al. Outcome of transplantation of organs procured from bacteremic donors1. Transplantation. 1999;68:1107-1111.

How to cite this article: Amdani SM, Du W, Aggarwal S. Outcome of pediatric heart transplantation in blood culture positive donors in the United States. Clin Transplant. 2018;32:e13249. https://doi.org/10.1111/ctr.13249 